\title{
$\begin{array}{ll}\text { Research Square } & \begin{array}{l}\text { Preprints are preliminary reports that have not undergone peer review. } \\ \text { They should not be considered conclusive, used to inform clinical practice, } \\ \text { or referenced by the media as validated information. }\end{array}\end{array}$
}

\section{Mealtime Caregiving Approaches and Behavioral Symptoms in Persons Living With Dementia: A Longitudinal, Observational \\ Study}

Ji Yeon Lee

Yonsei University Health System

Kyung Hee Lee ( $\nabla$ kyungheelee@yuhs.ac )

Yonsei University Health System

Eleanor McConnell

Duke University

\section{Research Article}

Keywords: Behavioral Symptom, Caregiving Approach, Mealtime, Person-centered Behavior, Persons Living with Dementia, Taskcentered Behavior

Posted Date: January 4th, 2021

DOl: https://doi.org/10.21203/rs.3.rs-130466/v1

License: (a) (1) This work is licensed under a Creative Commons Attribution 4.0 International License. Read Full License 


\section{Abstract}

Background: Behavioral symptoms during mealtime can prohibit persons living with dementia from obtaining sufficient nutrition. However, little research has examined the relationship between behavioral symptoms and caregiving approaches. This study examines this relationship and further explores which specific caregiver behaviors were related to behavioral symptoms among persons living with dementia.

Methods: A secondary data analysis was performed using 86 mealtime videos from a longitudinal, observational study. The videos were repeatedly taken at months 0,3 , and 6 with 30 persons living with dementia in one of four long-term care facilities. Video coding was performed using coding schemes modified from the Cohen-Mansfield Agitation Inventory for behavioral symptoms and the Person-/Task-Centered Behavior Inventory for caregiving approaches. Coding schemes for behavioral symptoms consisted of four categories: total duration, aggressive behavior, physically nonaggressive behavior, and verbally agitated behavior. Caregiving approaches consisted of ten-verbal/seven-nonverbal person-centered behavior codes, four-verbal/four-nonverbal taskcentered behavior codes, and no-verbal/no-nonverbal interaction codes. A mixed-effect model was conducted using variables such as demographics, medical information, cognitive status, depression, function, and caregiving approaches as fixed effects, participant as a random effect, and four categories of behavioral symptoms as dependent variables.

Results: The total duration of the Cohen-Mansfield Agitation Inventory was associated with no verbal response $(\beta=9.09)$ and taskcentered verbal behavior $(\beta=8.43)$, specifically verbal controlling $(\beta=7.87)$. Physically nonaggressive behavior was associated with no verbal response $(\beta=9.36)$. Verbally agitated behavior was associated with task-centered nonverbal behavior $(\beta=51.29)$, and specifically inappropriate touch $(\beta=59.05)$.

Conclusions: Mealtime is indispensable to dementia care, but best practices for mealtime have not been suggested when behavioral symptoms are present. Our findings revealed caregivers' task-centered behaviors and no interaction were related to behavioral symptoms of persons living with dementia. When caregivers encounter behavioral symptoms during mealtime, it is recommended to avoid no response and task-centered behaviors, especially verbal controlling and inappropriate touch, and to promote person-centered behaviors.

\section{Background}

The number of persons living with dementia was estimated at 50 million worldwide in 2019 [1]. In Korea, dementia affects approximately 750,000 people ( $10.16 \%$ of the population aged 65 and older), and $46.7 \%$ of long-term care residents have dementia [2]. Among persons with dementia living in long-term care residences, approximately $50 \%$ have lost the ability to feed themselves, due to progressive decline of cognitive and behavioral functions $[3,4]$.

Maintaining appropriate nutritional status among long-term care residents is an important consideration for health professionals, as malnutrition in long-term care has been documented in 30 to $60 \%$ of residents [5]. Persons living with dementia are at particularly high risk for malnutrition because they often develop dysphagia, the inability to eat independently, and dementiarelated behavioral symptoms such as agitation and aggression [6, 7]. Although a large number of persons living with dementia receive caregivers' assistance during mealtime, mealtime difficulties often interfere with obtaining sufficient nutrition, in part due to behavioral symptoms occurring during mealtime. In order to support adequate nutrition, it is necessary to identify caregiver factors related to behavioral symptoms and mealtime difficulties among persons living with dementia.

Studies have demonstrated that caregiving approaches were an important component for improving mealtime experience and preventing behavioral symptoms. A review paper showed that eight studies reported providing adequate feeding assistance could improve food intake [8], and an experimental study displayed food intake and feeding behaviors were different based on meal providers' hand-feeding techniques [9]. Additionally, a qualitative study described that limited or negative social interaction between resident and caregiver might agitate residents with dementia while knowledge of residents' preferences and abilities was essential to reduce agitation during mealtime [10]. Taken together, these studies suggest that a person-centered caregiving approach, providing care based on an individual's preferences and needs, would improve care quality during mealtimes and, in turn, help to maintain nutritional adequacy of persons living with dementia [11]. 
However, relatively few studies have investigated the influence of person-centered care on behavioral symptoms [12, 13]. Moreover, although some studies revealed person-centered care reduced behavioral symptoms among persons living with dementia when compared to standard care or task-centered care $[12,13]$, the association between specific caregiver behaviors and behavioral symptoms were not examined. If we could show that certain verbal or nonverbal behaviors are associated with specific behavioral symptoms during mealtime, then caregivers could avoid or promote individual behaviors to reduce behavioral symptoms and improve meal assistance, which could result in clinically meaningful improvements in nutritional status. Thus, the purpose of this study was to examine 1) whether caregiving approaches (i.e., person-centered vs. task-centered) were associated with behavioral symptoms of persons living with dementia during mealtime and 2) which specific behaviors among caregiving approaches were related to behavioral symptoms.

\section{Methods}

\section{Data Source and Participants}

This study analyzed data from a longitudinal, observational study conducted to explore the care-specific emotional expressions of persons living with dementia. Participants were eligible for the study if they were 65 years or older, diagnosed with dementia based on criteria from the Diagnostic and Statistical Manual of Mental Disorders, fourth edition, and had a Korean Mini Mental State Examination (K-MMSE) score lower than 24. For each participant, nine videos were taken at 0, 3, and 6 months for each of the three specific care situations including mealtime, personal care, and social activity. Since three participants dropped out of the study at three or six months, 30 participants with 258 videos were produced. Of these, this present study analyzed 86 mealtime videos from 30 participants.

\section{Variables and Measures}

\section{Person-Level Data}

Person-level data, collected only at baseline from participants' medical chart included demographic data such as age, sex, and education level, and medical information such as comorbidities and medications. Comorbidities were categorized according to the Cumulative Illness Rating Scale-Geriatric (CIRS-G) [14]. This tool is organized into 14 categories, and for diseases present in each category, a minimum of zero and a maximum of four points can be given according to its severity. The illness severity is calculated with the total score (0-56) divided by the number of corresponding categories (0-14). All medications taken by participants were classified as cardiovascular, diabetes, dementia, psychiatric, and other medications.

\section{Observation-Level Data}

Observation-level data, collected at 0, 3, and 6 months from the parent study included participants' behavioral symptoms, caregiving approaches, cognitive status, depression, and function using measures described below.

Participants' behavioral symptoms were evaluated using the Korean version of Cohen-Mansfield Agitation Inventory (CMAI-K) [15, 16]. This tool is composed of 29 items and organized into three categories: aggressive behavior (e.g., hitting, grabbing, verbal aggression, and so on), physically nonaggressive behavior (e.g., repetitious mannerisms, general restlessness, and so on), and verbally agitated behavior (e.g., complaining, negativism, repetitious sentences, and so on). A higher score means more behavioral symptoms in the original tool [17].

To measure caregiving approaches during mealtime, we used a behavioral coding scheme, which contained items from the PersonCentered Behavior Inventory (PCBI) and Task-Centered Behavior Inventory (TCBI) $[18,19]$. This coding scheme measured mealtime interaction between persons living with dementia and caregivers, and comprised verbal and nonverbal behaviors for each category of PCBI and TCBI. The verbal PCBI includes ten behaviors: greeting, asking the resident for help/cooperation, giving choices, assessing comfort, providing orientation, showing approval/interest/empathy, positive voice quality, and back-channel response. The nonverbal PCBI includes seven behaviors: resident-directed eye gaze, positive gestures, appropriate use of affectionate touch, assessing comfort nonverbally, adjusting to the resident's pace, proximity, and positive facial expressions. The verbal TCBI includes four behaviors: verbal controlling (i.e., interfering/directing tone or elderspeak), interrupting, changing topics, and controlling voice quality. The nonverbal TCBI includes four behaviors: ignoring, physically controlling, inappropriate touch, and outpacing. In 
addition to the PCBI/TCBI, no interaction codes (i.e., no verbal response and no nonverbal response) were added to the scheme to cover the entire video because there were parts of the video where caregivers did not display any verbal/nonverbal behaviors.

Cognitive status was measured by the K-MMSE and the Korean version of Clinical Dementia Rating (K-CDR). The K-MMSE is a 30item scale with a total of 30 points; a lower score indicates more impairment in cognition. Untestable cases were given -1 point in the K-MMSE [20]. The K-CDR is a 6-item scale with a total of 30 points, and its higher score denotes more severe dementia [21]. Depression was measured using the Korean version of Cornell Scale for Depression in Dementia (K-CSDD), which consists of 19 items with a total of 38 points, and a higher score implies a more depressive state [22]. Function was rated using the Korean version of Activities of Daily Living (K-ADL), which consists of seven items, with a higher score indicating more dependency [23, 24].

\section{Procedure}

After obtaining Institutional Review Board (IRB) approval, we extracted 86 mealtime videos (i.e., eating and feeding) from the parent study, which included 258 videos about three care situations (mealtime, personal care, and social activity). Since the videos contained images and voices of participants and caregivers that would allow them to be recognized, two research assistants (RAs) who managed and coded the videos were particularly well-trained on ethical issues such as confidentiality before starting the study. To ensure intra-rater/inter-rater reliability, we initially sampled $10 \%$ of the videos, and two coders coded the same video and compared results. After inter-rater reliability as measured by the kappa statistic reached 0.8 , the coding process was started. To ensure reliability between coders throughout the coding process, we conducted an additional reliability check after half the videos were coded.

We used the Noldus Observer ${ }^{\circledR}$ XT software for coding, using the items from the PCBI/TCBI and CMAl as codes. Among the PCBI and TCBI, the verbal behaviors were coded using instantaneous sampling and the nonverbal behavior were coded using continuous sampling. Instantaneous sampling counts how many times each verbal behavior appeared in the entire video (frequency) as the coder assigns the code that corresponded to specific caregiver behaviors every ten seconds. With continuous sampling, the coder assigns the code of nonverbal behaviors of interest whenever they began and finished so that the total time for each behavior could be calculated in seconds (duration) [25]. When caregivers showed no behaviors, the coder put no verbal response or no nonverbal response to provide mutually exclusive and exhaustive codes. Consistent with the PCBI/TCBI coding scheme, no interaction codes were calculated as a frequency for no verbal response and duration for no nonverbal response. The participant's behavioral symptoms were coded using the CMAl, which was also obtained through continuous sampling. We summed the total time for each behavioral symptom observed and categorized these behaviors into the three categories of the CMAl: aggressive behavior, physically nonaggressive behavior, and verbally agitated behavior. Throughout the whole process, when the coder could not decide which category a behavior belonged to, it was determined after a discussion with another researcher at the weekly meetings.

\section{Statistical analysis}

For statistical analysis of the frequency data, we counted the total number of times each behavior occurred in each video and grouped into person- or task-centered verbal behaviors. Then, the total frequency of person- or task-centered verbal behaviors were divided by the total time of each video (frequency per minute) since the total time of each video varied according to participants' eating pace. Similarly, we added the total seconds of each person-/task-centered nonverbal behavior of the caregivers and behavioral symptoms of the participant and divided the total time by the total time of each video (duration per minute) to account for the difference in video length; therefore, duration per minute referred to total seconds in which a specific action appeared in one minute.

Statistical analysis was conducted using the STATA 16.0 software (StataCorp, College Station, Texas, USA) and consisted of the following steps: 1) descriptive analysis to understand participants' characteristics, 2) a mixed-effect model to examine whether caregiving approaches were associated with participants' behavioral symptoms, and 3) a further analysis to determine which particular behavior among significant PCBI/TCBI, were associated with behavioral symptoms. The mixed-effect model was chosen because the data were repeated measures and therefore nested within participants. Both time points and facility were considered in the model. We controlled for the time variable (i.e., time points) to reflect change over time in behavioral symptoms; the facility 
was included to account for correlation for responses from participants of the same facility. Among various mixed-effect models, we used multilevel mixed-effects tobit regression fixing the lower limit at the minimum value of the dependent variable because behavioral symptom measures were continuous variables and left-censored with many zero values [26].

\section{Results}

The mean duration of videos was $17.58 \pm 8.17$ minutes. Table 1 shows a descriptive summary of the person-level and observationlevel data. Participants had a mean age of $85.63 \pm 6.67$ years and were mostly female (93.33\%). The mean CIRS-G score was 4.50 \pm 2.74 and the severity score was $1.75 \pm 0.71$. The number of medications taken was $6.83 \pm 3.50$ and $93.33 \%$ of participants were taking dementia medications.

Observation-level data included the values from three observation points at 0,3 , and 6 months. The mean score was $2.81 \pm 5.18$ in MMSE and $16.42 \pm 2.24$ in CDR, which indicated that most of the participants had a severe impairment in cognition. The mean score was $3.72 \pm 3.44$ in CSDD and 15\% of participants had a depressed state. The mean ADL was $18.51 \pm 2.21$ and $73 \%$ of participants had impaired physical function in their ADL. The mean duration of behaviors coded by the CMAl items was $7.94 \pm$ $27.62 \mathrm{sec} / \mathrm{min}$. In case of sub-categories of CMAl, the mean duration was $0.08 \pm 0.27 \mathrm{sec} / \mathrm{min}$ in aggressive behavior, $6.20 \pm 27.43$ $\mathrm{sec} / \mathrm{min}$ in physically nonaggressive behavior, and $1.65 \pm 4.41 \mathrm{sec} / \mathrm{min}$ in verbally agitated behavior.

\section{Caregiving Approaches Associated with Behavioral Symptoms}

Bivariate analysis was performed for total duration and three subcategories of the CMAI (i.e., total duration, aggressive, physically nonaggressive, and verbally agitated behavior). Each of the four CMAl categories was significantly related to different independent variables, but ADL, MMSE, and taking dementia medication had significant associations in most of the categories (result not shown). Based on this bivariate analysis and previous literature, ADL, MMSE, and taking dementia medication were set as covariates. Among these covariates, taking dementia medication was not included in the aggressive behavior model because all participants with aggressive behavior were taking dementia medication (Table 2). By controlling these covariates and allowing the participant as a random effect, variables from caregiving approaches (i.e., person-centered verbal/nonverbal behaviors, taskcentered verbal/nonverbal behaviors, and no verbal/nonverbal response) were used as independent variables in the multilevel mixed-effect regression.

Table 2 shows the result of the multilevel mixed-effect regression. The variables associated with CMAl total duration were taskcentered verbal behavior $(\beta=8.43, p=.040)$, no verbal response $(\beta=9.09, p=.017)$, and taking dementia medication $(\beta=-32.52, p$ $=.010)$. More specifically, participants displayed more behavioral symptoms if the caregivers spoke in a task-centered manner and showed no verbal response, and if the participants were not taking dementia medications. There was no associated factor in case of aggressive behavior. Physically nonaggressive behavior was associated with no verbal response $(\beta=9.36, p=.042)$; verbally agitated behavior was associated with task-centered nonverbal behavior $(\beta=51.29, p<.001)$. In other words, participants showed physically nonaggressive behavior when there was no verbal response and showed verbally agitated behavior when the caregivers acted in a task-centered way.

\section{Specific Caregiver's Behavior Associated with Behavioral Symptoms}

Using variables that showed significance in the multilevel mixed-effect regression, further analysis was performed to investigate which specific caregiver behaviors were associated with participants' behavioral symptoms (Table 3). After adjusting for ADL dependence, MMSE scores, facility, and use of dementia medications, both verbal controlling behaviors by the caregiver $(\beta=7.87, p$ $<.001)$ and no verbal response from the caregiver were significantly associated with greater total duration of CMAI behaviors $(\beta=$ $8.89, p<.001)$. With respect to the subcategory of the CMAI, inappropriate touching by the caregiver was significantly related to verbally agitated behavior $(\beta=59.05, p<.001)$; the more frequently the caregiver touched the participant, the more verbally agitated behaviors the participant displayed.

\section{Discussion}


Eating well is a complex process, which can be influenced by several factors [27, 28]. Among several factors, we focused on mealtime experience, particularly on the relationship between caregiving approaches and behavioral symptoms of persons living with dementia. In general, task-centered caregiving approaches were significantly associated with participants' behavioral symptoms, in accordance with a previous study, which reported that task-centered caregiver behaviors were more likely to precede behavioral symptoms [13]. For persons living with dementia, mealtimes can be perceived as a positive event, where hunger is relieved, in a pleasant environment, that allows for social stimulation, or as a negative event, a time when they are forced to do tasks that are unpleasant or uncomfortable. When the caregiver behaves in a task-centered manner, it could increase the Behavioral and Psychological Symptoms of Dementia (BPSD) because task-centered behaviors do not satisfy or reduce the unmet needs of persons living with dementia for relief of hunger or varied stimulation throughout the day [29, 30]. Although the importance of person-centered care has been emphasized and applied in dementia care, it is still reported that actual dementia care is work-oriented and uses medical management styles for behavioral symptoms. This study adds more evidence that the taskcentered approach is not an effective way to help persons living with dementia who manifest behavioral symptoms [31]. It is important to understand behavioral symptoms as a method that persons living with dementia use to communicate unmet needs rather than viewing these symptoms as disruptive behaviors. Therefore, health professionals need to develop competency in providing person-centered rather than task-centered care.

Our study revealed that specific caregiver behaviors were closely related to specific behavioral symptoms. When caregivers engaged in task-centered behaviors and also made verbally controlling statements, total behavioral symptom duration increased. Likewise, inappropriate touch by caregivers was related to verbally agitated behavior. Although a prior qualitative study suggests that specific caregiver behaviors influence behaviors of persons living with dementia, to the best of our knowledge, our study was the first study to examine this quantitatively using video-based observation. Our findings are consistent with the qualitative study [32] which found that negative caregiver actions, such as confronting, persuading, or bursting out in anger, tended to induce BPSD, whereas positive caregiver action, such as acknowledging and responding to patients, tended to reduce BPSD. Caregivers often use verbal communication or nonverbal touch behavior to induce the resident's response when the resident refuses the caregiver's instruction or guidance; however, persons living with dementia may misunderstand those intentions. Another prior study also stated that excessive or ambiguous stimuli can result in mealtime agitation [10]. Since there is scarce research focused on specific caregiver behaviors and participants' behavioral symptoms, future research is needed to confirm such a relationship. Turning now to what was already revealed, person-centered verbal and nonverbal communication is of particular importance in dementia care; furthermore, caregivers often stated they would benefit from more education [33,34]. The results of this study specifically show that more attention is needed to avoid certain behaviors which may cause behavioral symptoms.

In addition to the relationships between caregiver behaviors and resident BPSD, no interaction (e.g., no verbal response) between caregiver and resident was also related to behavioral symptoms. Previous studies reported that a lack of interaction between persons living with dementia and their surroundings were associated with BPSD [35] or resulted in mealtime agitation [10]. However, persons living with dementia were found to interact directly with the caregivers only $2.5 \%$ of the time per day [36]. Even then, except for work-related interactions, much of the interaction was carried out incompletely silence, with no verbal interaction [36]. Even though more interactions between caregivers and residents were expected during mealtime, similar findings were found in this study; the PCBI was 1.71 times per minute and the TCBI was 0.83 times per minute in average, whereas no interaction was found 6.52 times per minute (result not shown in tables). Obstacles, such as task-focused day-to-day care, workload pressure to get the task done, and a lack of education on how to communicate with persons living with dementia, might hinder caregivers from promoting interaction between caregivers and persons living with dementia $[34,36]$.

Collectively, it seems that a person-centered caregiving approach would achieve better results than a task-centered caregiving approach or no interaction when we encounter behavioral symptoms. Despite the lack of statistical significance, coefficient values of person-centered caregiving approach tended to have a negative relationship with behavioral symptoms. When interacting with persons living with dementia, because of their decline in linguistic ability, it is necessary to utilize verbal and nonverbal communication in an appropriate person-centered manner [37].

The study had limitations. We examined the association between caregiving approaches and behavioral symptoms, but not the causal relationship. Nevertheless, it revealed the relationship of specific caregiver behaviors (i.e., verbal controlling and inappropriate touch) to behavioral symptoms of persons living with dementia with a quantitative methodology. The sample should 
also be noted. The parent study gathered 258 videos from 30 participants based on the power analysis, but we extracted only 86 mealtime videos. Because of the small sample size, this study might not show that person-centered behaviors had a significant negative relationship with behavioral symptoms. Thus, we suggest a future study with a larger sample size and research design to reveal any causal relationships between caregiving approaches and behavioral symptoms.

\section{Conclusions}

In conclusion, mealtimes are vital to dementia care because they ensure adequate nutritional status and provide an opportunity for social interaction among persons living with dementia. Therefore, it is important to provide high-quality care by aiming for personcentered care, avoiding task-centered behavior, and promoting social interaction between persons living with dementia and caregivers. This study highlights that particular attention is needed to avoid overall task-centered approaches, specific behaviors such as verbal controlling and inappropriate touch, and a lack of interaction in the context of BPSD during mealtime. Our findings may provide further insight to enhance the quality of nursing care or mealtime interventions.

\section{Abbreviations}

BPSD: Behavioral and Psychological Symptoms of Dementia

CIRS-G: Cumulative Illness Rating Scale-Geriatric

CMAI-K: Korean version of Cohen-Mansfield Agitation Inventory

IRB: Institutional Review Board

K-ADL: Korean version of Activities of Daily Living

K-CDR: Korean version of Clinical Dementia Rating

K-CSDD: Korean version of Cornell Scale for Depression in Dementia

K-MMSE: Korean Mini Mental State Examination

PCBI: Person-Centered Behavior Inventory

TCBI: Task-Centered Behavior Inventory

\section{Declarations}

\section{Ethics approval and consent to participate}

This study was conducted in accordance with the Declaration of Helsinki [38]. The Yonsei University Institutional Review Board approved the study (ref no: Y-2019-0181). A written informed consent was obtained from all caregivers and persons living with dementia who had the capacity to give consent before participating in the study. If a person living with dementia was lacking the capacity to give consent, their next of kin gave written informed consent on behalf of the person living with dementia.

\section{Consent for publication}

Not applicable.

\section{Availability of data and materials}

The datasets generated and analyzed for the current study are not publicly available due to IRB agreements, but are available from the corresponding author on reasonable request.

\section{Competing interests}

The authors declare that they have no competing interests. 


\section{Funding}

This work was supported by Basic Science Research Programs through the National Research Foundation of Korea (NRF) funded by the Ministry of Education (grant numbers NRF-2017R1D1A1B03028534 and NRF-2020R1A6A1A03041989).

\section{Authors' contributions}

The concept and design of the study: ESM, JYL, KHL; data analysis and interpretation JYL and KHL; drafting and revising article, and approval of the final manuscript: ESM, JYL, KHL.

\section{Acknowledgements}

We would like to acknowledge Bora Kim, a doctoral student at Yonsei University College of Nursing for data collection and coding.

\section{References}

1. World Health Organization. 10 facts on dementia 2019. https://www.who.int/features/factfiles/dementia/en/. Accessed 13 Nov 2020.

2. National Institute of Dementia. Korean dementia observatory 2019. https://www.nid.or.kr/info/dataroom_view.aspx?bid=209. Accessed 13 Nov 2020.

3. LeClerc CM, Wells DL, Sidani S, Dawson P, Fay J. A feeding abilities assessment for persons with dementia. Alzheimers Care Today. 2004;5(2):123-33.

4. Volicer L, Seltzer B, Rheaume Y, Fabiszewski K, Herz L, Shapiro R, et al. Progression of Alzheimer-type dementia in institutionalized patients: A cross-sectional study. J Appl Gerontol. 1987;6(1):83-94.

5. Namasivayam AM, Steele CM. Malnutrition and dysphagia in long-term care: A systematic review. J Nutr Gerontol Geriatr. 2015;34(1):1-21.

6. LeClerc CM, Sidani S, Wells DL, MacDonald G, Rivera T, Saunders S. Clinical utility of the feeding abilities assessment. Alzheimers Care Today. 2004;5(2):134-43.

7. Reed PS, Zimmerman S, Sloane PD, Williams CS, Boustani M. Characteristics associated with low food and fluid intake in long-term care residents with dementia. Gerontologist. 2005;45(suppl_1):74-80.

8. Douglas JW, Lawrence JC. Environmental considerations for improving nutritional status in older adults with dementia: A narrative review. J Acad Nutr Diet. 2015;115(11):1815-31.

9. Batchelor-Murphy MK, McConnell ES, Amella EJ, Anderson RA, Bales CW, Silva S, et al. Experimental comparison of efficacy for three handfeeding techniques in dementia. J Am Geriatr Soc. 2017;65(4):e89-e94.

10. Bergland $\AA$, Johansen H, Sellevold GS. A qualitative study of professional caregivers' perceptions of processes contributing to mealtime agitation in persons with dementia in nursing home wards and strategies to attain calmness. Nurs Open. 2015;2(3):119-29.

11. Fazio S, Pace D, Flinner J, Kallmyer B. The fundamentals of person-centered care for individuals with dementia. Gerontologist. 2018;58(suppl_1):S10-S9.

12. Chenoweth L, King MT, Jeon YH, Brodaty H, Stein-Parbury J, Norman R, et al. Caring for Aged Dementia Care Resident Study (CADRES) of person-centred care, dementia-care mapping, and usual care in dementia: A cluster-randomised trial. Lancet Neurol. 2009;8(4):317-25.

13. Gilmore-Bykovskyi AL, Roberts TJ, Bowers BJ, Brown RL. Caregiver person-centeredness and behavioral symptoms in nursing home residents with dementia: A timed-event sequential analysis. Gerontologist. 2015;55(Suppl_1):S61-S6.

14. Miller MD, Paradis CF, Houck PR, Mazumdar S, Stack JA, Rifai AH, et al. Rating chronic medical illness burden in geropsychiatric practice and research: Application of the Cumulative Illness Rating Scale. Psychiatry Res. 1992;41(3):237-48.

15. Cohen-Mansfield J. Instruction manual for the Cohen-Mansfield agitation inventory (CMAI). Research Institute of the Hebrew Home of Greater Washington. 1991. 
16. Suh GH. Agitated behaviours among the institutionalized elderly with dementia: Validation of the Korean version of the CohenMansfield Agitation Inventory. Int J Geriatr Psychiatry. 2004;19(4):378-85.

17. Cohen-Mansfield J, Marx MS, Rosenthal AS. A description of agitation in a nursing home. J Gerontol. 1989;44(3):M77-M84.

18. Gilmore-Bykovskyi AL. Caregiver person-centeredness and behavioral symptoms during mealtime interactions: Development and feasibility of a coding scheme. Geriatr Nurs. 2015;36(2):S10-S5.

19. Lann-Wolcott H, Medvene LJ, Williams K. Measuring the person-centeredness of caregivers working with nursing home residents with dementia. Behav Ther. 2011;42(1):89-99.

20. Kang Y, Na DL, Hahn S. A validity study on the Korean Mini-Mental State Examination (K-MMSE) in dementia patients. J Korean Neurol Assoc. 1997;15(2):300-8.

21. Choi SH, Na DL, Lee BH, Hahm DS, Jeong JH, Yoon SJ, et al. Estimating the validity of the Korean version of expanded Clinical Dementia Rating (CDR) scale. J Korean Neurol Assoc. 2001;19(6):585-91.

22. Lim HK, Hong SC, Won WY, Hahn C, Lee CU. Reliability and validity of the Korean version of the Cornell Scale for Depression in Dementia. Psychiatry Investig. 2012;9(4):332-8.

23. Won C, Rho Y, Kim S, Cho B, Lee Y. The validity and reliability of Korean Activities of Daily Living (K-ADL) scale. J Korean Geriatr Soc. 2002;6(2):98-106.

24. Won C, Yang K, Rho Y, Kim S, Yoon J, Cho K, et al. The development of Korean activities of daily living (K-ADL) and Korean instrumental activities of daily living (K-IADL) scale. J Korean Geriatr Soc. 2002;6(2):107-20.

25. Noldus Information Technology. The observer XT, version 12.5. Wageningen: Noldus Information Technology; 2015.

26. StataCorp. Stata multilevel mixed-effects reference manual: Release 16. College Station, TX: StataCorp L.L.C.; 2019.

27. Keller H, Carrier N, Duizer L, Lengyel C, Slaughter S, Steele C. Making the Most of Mealtimes (M3): Grounding mealtime interventions with a conceptual model. J Am Med Dir Assoc. 2014;15(3):158-61.

28. Watkins R, Goodwin VA, Abbott RA, Backhouse A, Moore D, Tarrant M. Attitudes, perceptions and experiences of mealtimes among residents and staff in care homes for older adults: A systematic review of the qualitative literature. Geriatr Nurs. 2017;38(4):325-33.

29. Algase DL, Beck C, Kolanowski A, Whall A, Berent S, Richards K, et al. Need-driven dementia-compromised behavior: An alternative view of disruptive behavior. Am J Alzheimers Dis. 1996;11(6):10-9.

30. Hall GR, Buckwalter KC. Progressively lowered stress threshold: A conceptual model for care of adults with Alzheimer's disease. Arch Psychiatr Nurs. 1987;1(6):399-406.

31. Touhy TA. Dementia, personhood, and nursing: Learning from a nursing situation. Nurs Sci Q. 2004;17(1):43-9.

32. Song J-A, Park M, Park J, Cheon HJ, Lee M. Patient and caregiver interplay in behavioral and psychological symptoms of dementia: Family caregiver's experience. Clin Nurs Res. 2018;27(1):12-34.

33. Machiels M, Metzelthin SF, Hamers JPH, Zwakhalen SMG. Interventions to improve communication between people with dementia and nursing staff during daily nursing care: A systematic review. Int J Nurs Stud. 2017;66:37-46.

34. Page S, Hope K. Towards new ways of working in dementia: Perceptions of specialist dementia care nurses about their own level of knowledge, competence and unmet educational needs. J Psychiatr Ment Health Nurs. 2013;20(6):549-56.

35. Arai A, Khaltar A, Ozaki T, Katsumata Y. Influence of social interaction on behavioral and psychological symptoms of dementia over 1 year among long-term care facility residents. Geriatr Nurs. 2020; doi:10.1016/j.gerinurse.2020.09.008.

36. Ward R, Vass AA, Aggarwal N, Garfield C, Cybyk B. A different story: Exploring patterns of communication in residential dementia care. Ageing \& Society. 2008;28:629-51.

37. Windle G, Algar-Skaife K, Caulfield M, Pickering-Jones L, Killick J, Zeilig H, et al. Enhancing communication between dementia care staff and their residents: An arts-inspired intervention. Aging Ment Health. 2020;24(8):1306-15.

38. World Medical Association. World medical association declaration of Helsinki: Ethical principles for medical research involving human subjects. J Am Med Assoc. 2013;310(20):2191-4.

\section{Tables}


Table 1. Person-level and Observation-level Data

\begin{tabular}{|c|c|c|}
\hline Variables & Mean (SD) & $\mathrm{n}(\%)$ \\
\hline \multicolumn{3}{|l|}{ Person-level data $(n=30)$} \\
\hline Age & $85.63(6.67)$ & \\
\hline \multicolumn{3}{|l|}{ Sex } \\
\hline Female & & $28(93.33)$ \\
\hline Male & & $2(6.98)$ \\
\hline \multicolumn{3}{|l|}{ Education level } \\
\hline$<$ Middle school (6 years of education) & & $16(53.33)$ \\
\hline$\geq$ Middle school & & $14(46.67)$ \\
\hline \multicolumn{3}{|l|}{ CIRS-G } \\
\hline Total score & $4.50(2.74)$ & \\
\hline Severity score $†$ & $1.75(0.71)$ & \\
\hline Total number of medications & $6.83(3.50)$ & \\
\hline Taking dementia medication & - & \\
\hline Yes & & $28(93.33)$ \\
\hline No & & $2(6.67)$ \\
\hline \multicolumn{3}{|l|}{ Observation-level data $(n=86)$} \\
\hline MMSE score & $2.81(5.18)$ & \\
\hline CDR score & $16.42(2.24)$ & \\
\hline CSDD score & $3.72(3.44)$ & \\
\hline ADL score & $18.51(2.21)$ & \\
\hline \multicolumn{3}{|l|}{ CMAI } \\
\hline Total duration & $7.94(27.62)$ & \\
\hline Aggressive behavior & $0.08(0.27)$ & \\
\hline Physically nonaggressive behavior & $6.20(27.43)$ & \\
\hline Verbally agitated behavior & $1.65(4.41)$ & \\
\hline
\end{tabular}

Note. $\mathrm{ADL}=$ Activities of Daily Living; $\mathrm{CDR}=$ Clinical Dementia Rating; $\mathrm{CIRS}-\mathrm{G}=$ Cumulative IIIness Rating Scale-Geriatric; $\mathrm{CMAI}=$ Cohen-Mansfield Agitation Inventory; CSDD = Cornell Scale for Depression in Dementia; MMSE= Mini Mental Status Exam.

† Total CIRS-G score / total number of categories endorsed.

Table 2. Caregiving Approaches Associated with Behavioral Symptoms of Persons Living with Dementia during Mealtime 


\begin{tabular}{|c|c|c|c|c|c|c|c|c|c|c|c|c|}
\hline \multirow[b]{2}{*}{ Variables } & \multicolumn{3}{|c|}{ CMAl total durationt } & \multicolumn{3}{|c|}{ Aggressive behaviort } & \multicolumn{3}{|c|}{$\begin{array}{l}\text { Physically nonaggressive } \\
\text { behaviort }\end{array}$} & \multicolumn{3}{|c|}{$\begin{array}{l}\text { Verbally agitated } \\
\text { behaviort }\end{array}$} \\
\hline & Coeff & SE & $\begin{array}{l}P- \\
\text { Value }\end{array}$ & Coeff & SE & $\begin{array}{l}P- \\
\text { Value }\end{array}$ & Coeff & SE & $\begin{array}{l}P- \\
\text { Value }\end{array}$ & Coeff & SE & $\begin{array}{l}P \text { - } \\
\text { Value }\end{array}$ \\
\hline ADL & -0.08 & 1.05 & .939 & 0.03 & 0.19 & .863 & -0.47 & 1.60 & .767 & -0.31 & 0.40 & .444 \\
\hline MMSE & -0.37 & 0.38 & .329 & -0.07 & 0.06 & .229 & -0.97 & 0.66 & .140 & -0.12 & .014 & .382 \\
\hline $\begin{array}{l}\text { Taking } \\
\text { dementia } \\
\text { medication }\end{array}$ & -32.52 & 12.66 & .010 & - & - & - & -108.48 & 49207.54 & .998 & -1.22 & 4.39 & .781 \\
\hline \multicolumn{13}{|l|}{$\begin{array}{l}\text { Caregivers' } \\
\text { approaches }\end{array}$} \\
\hline \multicolumn{13}{|l|}{$\begin{array}{l}\text { Person- } \\
\text { centered } \\
\text { behavior }\end{array}$} \\
\hline $\begin{array}{l}\text { Verbal } \\
\text { behavior }\end{array}$ & 8.63 & 4.71 & .067 & -5.24 & 5.32 & .325 & 7.79 & 6.41 & .224 & -1.44 & 2.15 & .503 \\
\hline $\begin{array}{l}\text { Nonverbal } \\
\text { behavior }\end{array}$ & -6.80 & 26.13 & .795 & 26.83 & 31.45 & .394 & -18.99 & 33.95 & .576 & 10.64 & 10.73 & .321 \\
\hline \multicolumn{13}{|l|}{$\begin{array}{l}\text { Task- } \\
\text { centered } \\
\text { behavior }\end{array}$} \\
\hline $\begin{array}{l}\text { Verbal } \\
\text { behavior }\end{array}$ & 8.43 & 4.10 & .040 & -5.44 & 5.33 & .308 & 8.32 & 4.98 & .095 & -1.27 & 1.99 & .524 \\
\hline $\begin{array}{l}\text { Nonverbal } \\
\text { behavior }\end{array}$ & 42.19 & 26.16 & .107 & 28.85 & 31.81 & .364 & 0.93 & 32.07 & .977 & 51.29 & 10.99 & $<.001$ \\
\hline \multicolumn{13}{|l|}{$\begin{array}{l}\text { No } \\
\text { interaction }\end{array}$} \\
\hline $\begin{array}{l}\text { No verbal } \\
\text { response }\end{array}$ & 9.09 & 3.80 & .017 & -5.30 & 5.31 & .318 & 9.36 & 4.59 & .042 & -1.95 & 1.90 & .304 \\
\hline $\begin{array}{l}\text { No } \\
\text { nonverbal } \\
\text { response }\end{array}$ & 1.64 & 22.73 & .942 & 28.92 & 31.89 & .365 & 0.37 & 27.57 & .989 & 6.47 & 9.46 & .494 \\
\hline \multicolumn{13}{|l|}{ Time } \\
\hline Baseline & Ref & & & & & & & & & & & \\
\hline 3 month & 2.40 & 2.07 & .246 & -0.10 & 0.33 & .762 & .012 & 3.15 & .969 & -0.01 & 0.96 & .995 \\
\hline 6 month & -1.36 & 2.34 & .562 & 0.56 & 0.32 & .086 & -0.04 & 3.36 & .991 & -1.55 & 1.05 & .139 \\
\hline
\end{tabular}

Note. $\mathrm{ADL}=$ Activities of Daily Living; Coeff = Coefficient; MMSE = Mini Mental Status Exam.

†Analysis included dummy variables for study facilities to control for their effects, but output was suppressed to protect confidentiality.

Table 3. Specific Caregiver Behavior Associated with Behavioral Symptoms of Persons Living with Dementia during Mealtime 


\begin{tabular}{|c|c|c|c|c|c|c|}
\hline \multirow[b]{2}{*}{ Variables } & \multicolumn{3}{|c|}{ CMAl total duration $\dagger$} & \multicolumn{3}{|c|}{ Verbally agitated behavior +} \\
\hline & Coeff & SE & $P$-Value & Coeff & SE & $P$-Value \\
\hline ADL & 0.66 & 1.31 & .618 & -0.07 & 0.34 & .843 \\
\hline MMSE & -0.53 & 0.46 & .253 & -0.19 & .012 & .098 \\
\hline Taking dementia medication & -32.21 & 15.74 & .041 & -1.09 & 3.70 & .769 \\
\hline \multicolumn{7}{|l|}{ Specific caregivers' approaches } \\
\hline \multicolumn{7}{|l|}{ Task-centered verbal behavior } \\
\hline Verbal controlling & 7.87 & 2.23 & $<.001$ & - & & \\
\hline Changing topic & 39.17 & 30.52 & .199 & - & & \\
\hline Controlling voice quality & 68.35 & 211.15 & .746 & - & & \\
\hline \multicolumn{7}{|l|}{ No interaction } \\
\hline No verbal response & 8.89 & 0.47 & $<.001$ & - & & \\
\hline \multicolumn{7}{|c|}{ Task-centered nonverbal behavior } \\
\hline Ignoring & - & & & 292.89 & 157.11 & .062 \\
\hline Physically Controlling & - & & & 23.51 & 12.98 & .070 \\
\hline Inappropriate touch & - & & & 59.05 & 8.11 & $<.001$ \\
\hline Outpacing & - & & & 11.24 & 39.24 & .775 \\
\hline \multicolumn{7}{|l|}{ Time } \\
\hline Baseline & \multicolumn{6}{|c|}{ Reference } \\
\hline 3 month & 2.51 & 2.51 & .318 & -0.22 & 0.90 & .807 \\
\hline 6 month & -1.09 & 2.81 & .698 & -1.10 & 1.01 & .274 \\
\hline
\end{tabular}

Note. ADL = Activities of Daily Living; CMAI = Cohen-Mansfield Agitation Inventory Coeff $=$ Coefficient; MMSE = Mini Mental Status Exam.

†Analysis included dummy variables for study facilities to control for their effects, but output was suppressed to protect confidentiality. 